\title{
The four worlds of carbon
}

\author{
Simon H. Friedman explores the various ways in which carbon is inherently tied to our lives - beyond its \\ elegant, treasured role in organic chemistry.
}

T he organic chemist's view of carbon can be like the New Yorker's view of the world, which to them ends at the edge of Manhattan. For the organic chemist, carbon is the element that makes the beautiful, predictable, regular scaffolds of drugs, pesticides and dyes: all that wonderful stuff that saves lives, increases crop yields and allows for the convenient printing of T-shirts with timely messages. And all constructed with the enticing angles that Pauling explained but that Euclid and the ancients conceived (the $180^{\circ}, 120^{\circ}$ and $109.5^{\circ}$ of $s p$-, $s p^{2}$ - and $s p^{3}$-hybridized carbon).

The diversity of stable structures that are possible with carbon is unrivalled in the periodic table. With the addition of the fullerenes in the 1980s, the already impressive list of allotropic forms of carbon (including diamond, graphite and amorphous carbon) further expanded. And one estimate is that there are more possible carbon-based small molecules than there are atoms in the universe. This suggests continued employment for organic chemists for the foreseeable future.

\section{The diversity of stable structures that are possible with carbon is unrivalled in the periodic table.}

Yet, in the same way in which there is an entire world west of the Hudson river, there are entire worlds of carbon that have had an equal if not bigger impact on our lives. At the risk of offending the delicate sensibilities of some organic chemists, and for the sake of completeness, I am forced to elaborate on these now.

If organic chemistry is the first world of carbon, then the second is steel. Without carbon you still have iron, which is just fine

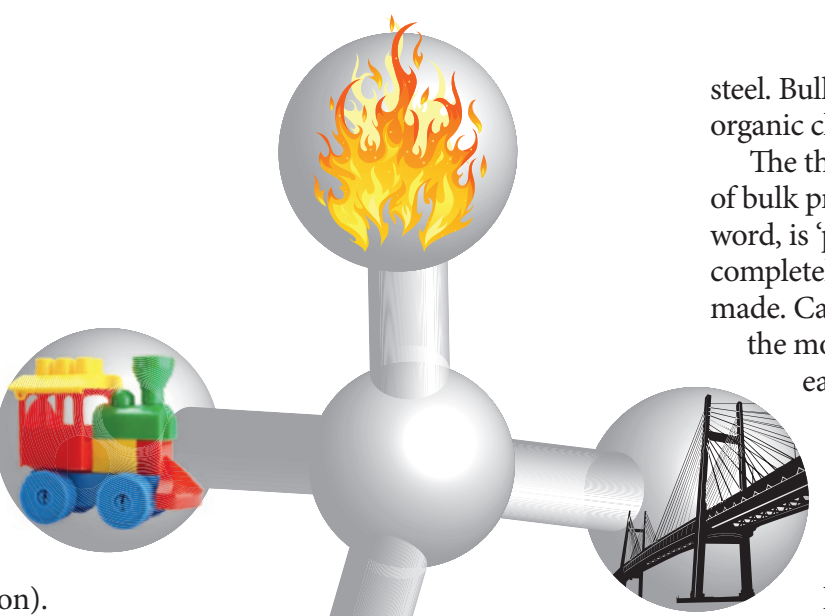

steel. Bulk properties; you can almost hear the organic chemists shuddering.

The third world of carbon is also a world of bulk properties. And that world, in a word, is 'plastics'. Plastics, or polymers, have completely reshaped the way things are made. Carbon allows for the construction of

the monomers that conveniently link to each other to make a wide diversity of polymers that have all sorts of useful properties, for example mouldability or biodegradability. An item that needed dozens of operations to machine in the first half of the twentieth century could be replaced in the second half by one made with one squirt of polymer into an injection mould. Owners of intraocular lenses and Happy Meal toys the world over rejoiced.

The fourth and final world of carbon is the world of energy. Carbon is the major source of energy our civilization runs on: crude oil, coal and natural gas. These carbon sources are simply burned to drive pistons or turbines and in the process create carbon dioxide.

if all you need to do is shoe a horse, but not quite up to the task of making things that are large and durable. Add about one per cent of carbon to your iron, however, and you have made steel - you can now construct useful things, like bulldozers and buildings that are half a mile high. This effect of carbon arises from structural characteristics. By itself, iron forms a regular crystalline lattice that consists of closely packed planes that can slip over each other. The slipping of these planes allows iron to fail structurally under relatively light loads.

Carbon helps to solve this problem because carbon atoms find a niche in interstitial sites of the iron lattice. Although irregularly located, they give rise to interactions that prevent the planes of iron atoms from slipping over each other, leading to an increase in strength for the resultant steel. Here, however, there is no atomic-level aesthetic at play, no regularity and no appealing geometry. In fact, that percentage of carbon can even vary, resulting in different bulk properties hardness, ductility, tensile strength - of the
Carbon dioxide is the final thermodynamic sink, because the two oxygen-carbon double bonds formed are strong, and there is nowhere lower on the energy landscape for carbon to conveniently go.

But for all the roles adopted by carbon in its many worlds, to the organic chemist, simply burning carbon for its energy must surely be akin to burning your books when you are cold, or eating next year's seeds when you are hungry. It suggests a level of desperation and a betrayal of the wonders the carbon atom has the potential to create. Perhaps it is in the refined aesthetic of the organic chemist that we can find an important message about the beauty of carbon that can be delivered to the rest of the world.

SIMON H. FRIEDMAN is an Associate Professor in the Division of Pharmaceutical Sciences, University of Missouri-Kansas City, 2464 Charlotte Street, NHSB 3245, Kansas City, Missouri 64108, USA. e-mail: friedmans@umkc.edu
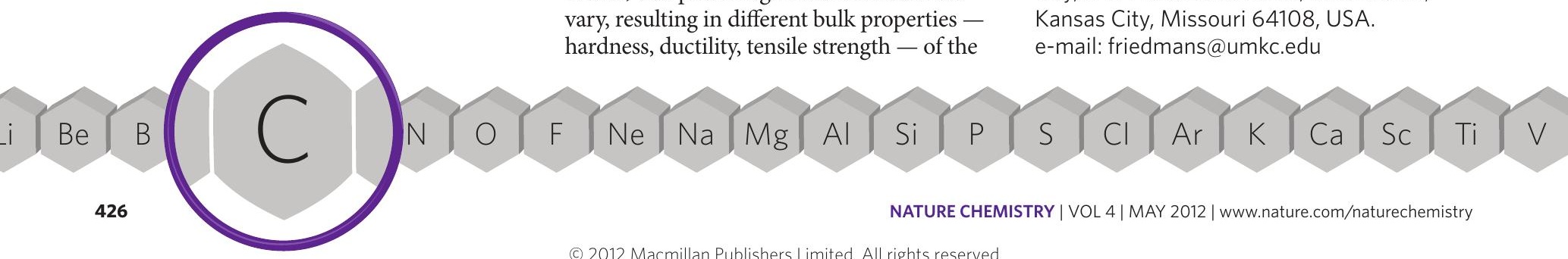